\title{
Novos modelos de armadilhas de emergência para captura de parasitoides de ovos endofíticos
}

\author{
New models of emergence traps for endophytic egg parasitoids capture
}

\author{
Rodrigo Souza Santos ${ }^{\mathrm{I}}$ Valmir Antonio CostaII Fernando da Silva Fonseca ${ }^{\mathrm{III}}$
}

\begin{abstract}
Para estudos de seleção de linhagens de inimigos naturais provenientes do campo, de comportamento ou mesmo de taxonomia, a captura de insetos vivos é de grande importância. Uma das alternativas para obtenção de parasitoides (Hymenoptera) adultos é a utilização de armadilhas de emergência. Sendo assim, o objetivo deste trabalho foi propor dois modelos de armadilhas de emergência (armadilhas do tipo "caixa" e "garrafa"), para obtenção de parasitoides vivos de ovos endofíticos. Os dois modelos de armadilhas propostas foram eficientes na captura de parasitoides vivos. Entretanto, foi observada uma maior captura de espécimes na armadilha do tipo "caixa" em relação à do tipo "garrafa", decorrente de uma maior armazenagem de folíolos no interior desta. A utilização de cada um dos modelos dependerá do tipo de pesquisa a ser realizada, do custo/benefício da sua confecção e da quantidade de parasitoides necessários para realização do estudo.
\end{abstract}

Palavras-chave: Erythmelus tingitiphagus, Mymaridae, Leptopharsa heveae, Tingidae.

\section{ABSTRACT}

For strain selection studies of natural enemies from the field, studies of behavior or even of taxonomy, capture of alive insects are of great importance. One alternative for obtaining adult parasitoids (Hymenoptera) is the use of emergency traps. Therefore, the objective of this work was to propose two models of emergency traps (traps like "box" and "bottle"), for obtaining alive endophytic egg parasitoids. The two models proposed were efficient in the capture of alive parasitoids, however a larger capture of specimens was observed in the "box" trap in relation to the e "bottle", due to larger folioles storage inside the same. The use of each one of the models will depend on the research which is being accomplished, the cost/benefit to built it, the amount parasitoids necessary to accomplish the study.

Key words: Erythmelus tingitiphagus, Mymaridae, Leptopharsa heveae, Tingidae.

As armadilhas foram uma das primeiras ideias utilizadas para capturar ou destruir insetos e monitorar populações de pragas em trabalhos de levantamento da fauna desses artrópodes em determinadas áreas (NAKANO \& LEITE, 2000).

Uma armadilha pode ser definida como um processo mecânico, físico ou químico que captura um organismo. Elas podem ser classificadas segundo sua finalidade, conforme o mecanismo de funcionamento e atração, segundo a exigência do operador, ou ainda de acordo com o tipo de inseto que captura (NAKANO \& LEITE, 2000). O desempenho de uma armadilha depende do seu local de instalação, da época do ano, das condições climáticas e do tipo de atraente, se utilizado. Um pouco de criatividade pode dar subsídios para modificações, melhorias, ou mesmo desenvolvimento de novos modelos (SCHAUFF, 1986).

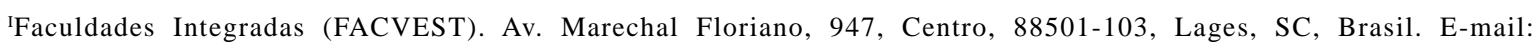
santos_rss@hotmail.com. Autor para correspondência.

IIInstituto Biológico, Agência Paulista de Tecnologia dos Agronegócios, Campinas, SP, Brasil.

IIIEmpresa "Plantações E. Michelin Ltda.”, Itiquira, MT, Brasil. 
Um dos pontos cruciais para o estabelecimento de uma colônia de insetos parasitoides é a obtenção de espécimes vivos em quantidade adequada, e uma das alternativas para a obtenção de espécimes adultos seria a utilização de armadilhas de emergência.

Uma armadilha de emergência é qualquer dispositivo que impeça os insetos adultos de dispersar quando estes emergirem de suas fases imaturas em qualquer substrato, como terra, tecido de plantas ou água (SCHAUFF, 1986).

Estimativas indicam que o número de espécies de parasitoides descritas nas ordens Hymenoptera e Diptera deve dobrar ou triplicar, já que há muitas espécies desconhecidas com esse hábito de vida (LEWINSOHN et al., 2001).

São escassas as armadilhas projetadas para captura de insetos vivos, e armadilhas destinadas à captura de insetos endofíticos teriam grande utilização em estudos taxonômicos, etológicos e de criação em laboratório, facilitando a obtenção dos insetos vivos. Nesse sentido, o objetivo deste trabalho foi propor dois novos tipos de armadilhas de emergência para captura de parasitoides vivos de insetos com postura endofítica (sob tecido foliar), utilizando como modelo de estudo o percevejo de renda da seringueira, Leptopharsa heveae Drake \& Poor (Hemiptera: Tingidae), e o parasitoide de ovos Erythmelus tingitiphagus (Soares) (Hymenoptera: Mymaridae).

O estudo foi desenvolvido na fazenda da empresa "Plantações E. Michelin Ltda.”, localizada no Município de Itiquira, Mato Grosso (MT) (17²2’23”S, $54^{\circ} 44^{\prime} 23^{\prime}$ 'W), no período de agosto de 2006 a janeiro de 2007. Semanalmente, folíolos maduros de seringueira (Hevea brasiliensis Müell. Arg.) que apresentavam sintomas de ataque de $\boldsymbol{L}$. heveae foram coletados no terço inferior da copa, em árvores dos clones PR 255 e RRIM 600, os quais apresentaram maiores níveis de infestação no período. A presença de posturas de $\boldsymbol{L}$. heveae foi confirmada, observando os folíolos sob microscópio estereoscópico. O número de ovos endofíticos por folíolo não foi contabilizado nos ensaios. No laboratório, os folíolos foram lavados em solução de hipoclorito de sódio (1,5\%), para remoção de impurezas e ovos de outros insetos externos às folhas e, em seguida, foram enxaguados em água destilada e mantidos em papel absorvente até a secagem, seguindo a metodologia adaptada do trabalho de COSTA et al. (2003). Os folíolos foram transferidos para dois modelos de armadilhas de emergência: do tipo "caixa" (Figuras 1A, B e C) e outro do tipo "garrafa" (Figuras 2A, B, C, D e E), mantidos em sala climatizada

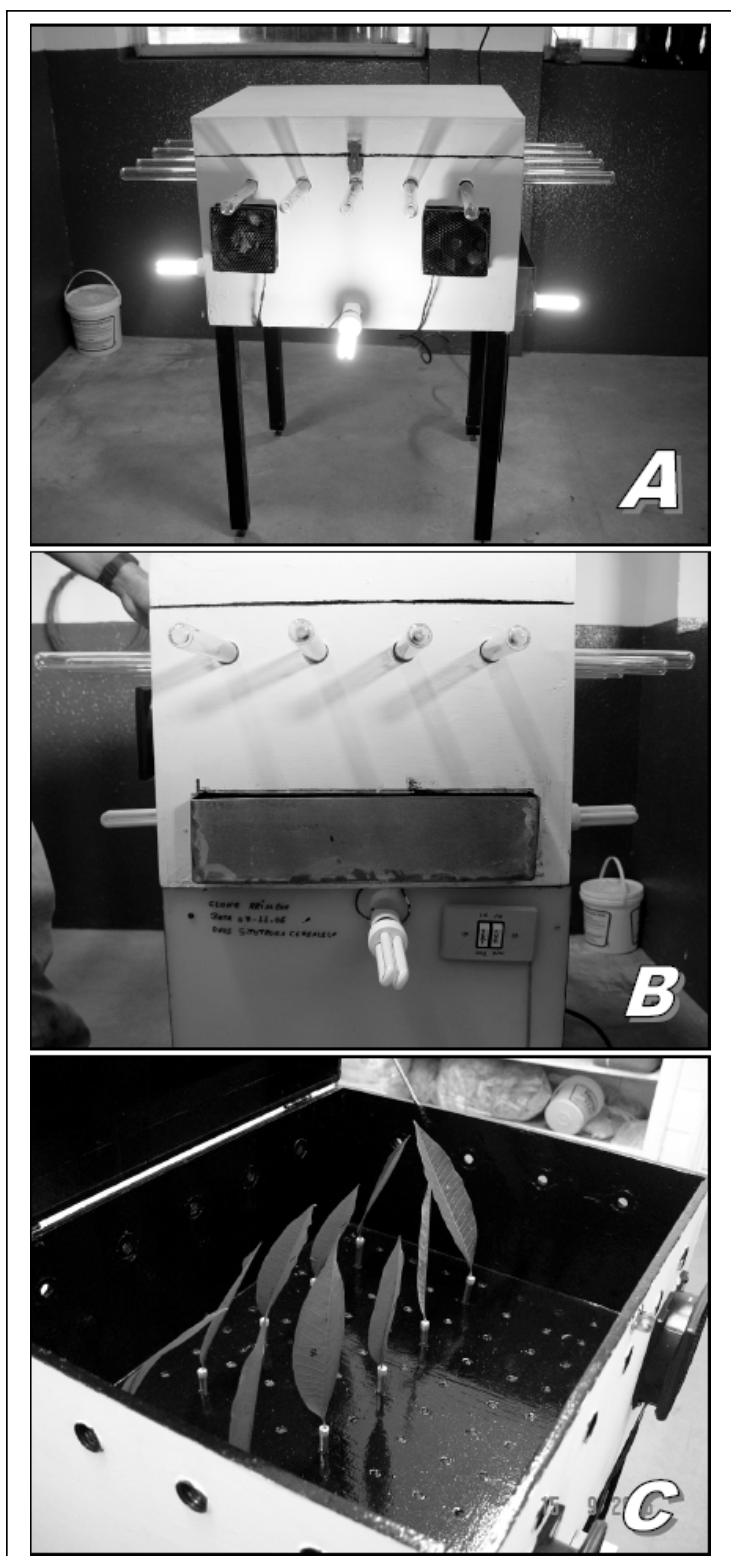

Figura 1 - Armadilha de emergência do tipo “caixa”: A. Aspecto externo da armadilha em funcionamento; B. Detalhe da bandeja contendo água e dos interruptores; C. Posicionamento dos folíolos de seringueira no interior da armadilha.

a $25 \pm 1^{\circ} \mathrm{C}$ e fotofase de 12 horas. Foram realizados seis ensaios para cada um dos modelos desenvolvidos durante o estudo.

Descrição e características das armadilhas de emergência

A) Armadilha do tipo "caixa” - Construída em madeira, com dimensões de $34 \mathrm{~cm}$ de altura x $60 \mathrm{~cm}$ de comprimento $\mathrm{x} 47 \mathrm{~cm}$ de largura, com uma tampa com

Ciência Rural, v.39, n.7, out, 2009. 


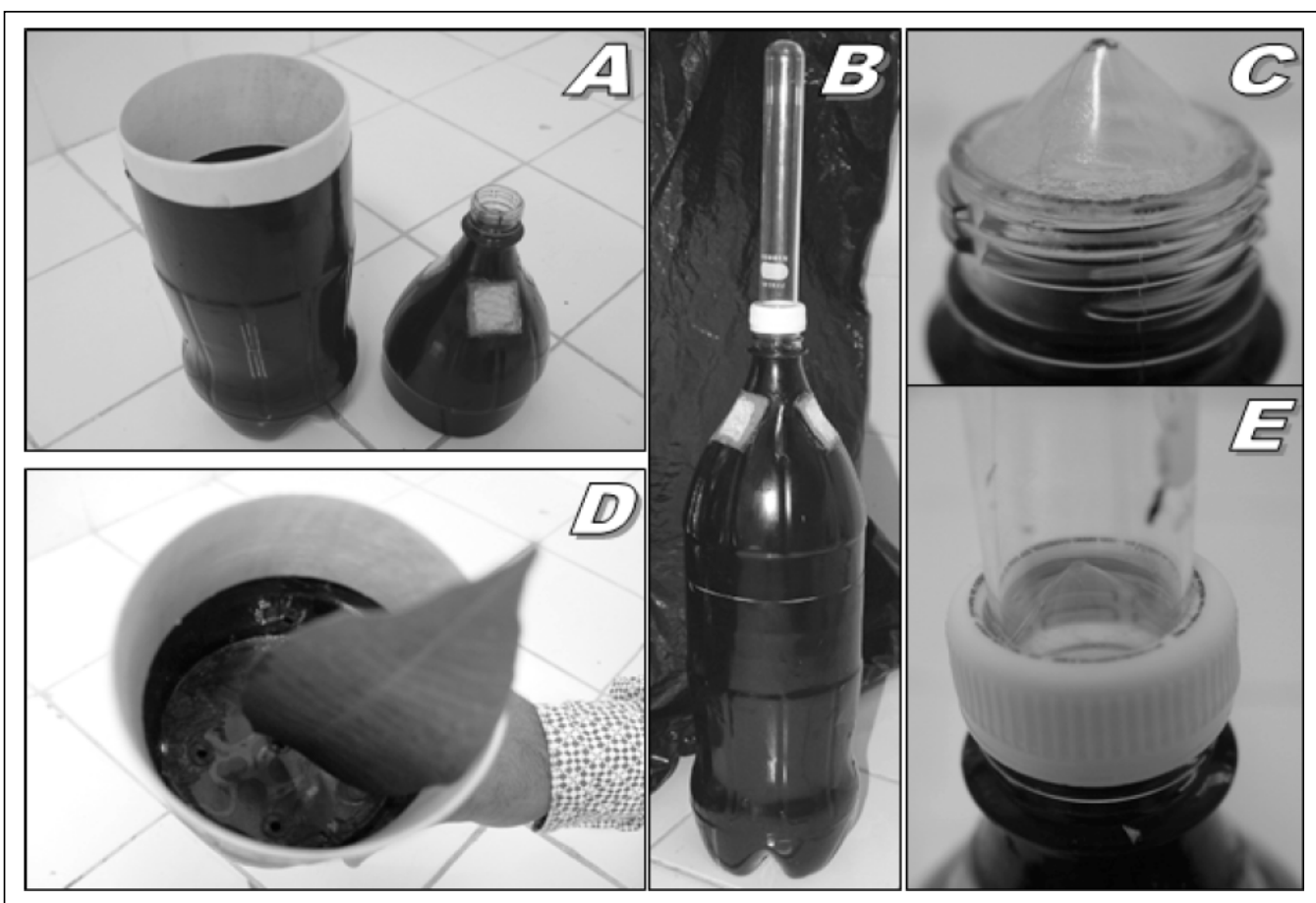

Figura 2 - Armadilha de emergência do tipo "garrafa”: A. Aspecto externo da armadilha desmontada; B. Armadilha montada; C. Detalhe do funil plástico; D. Posicionamento do folíolo de seringueira no interior da armadilha; E. Detalhe do encaixe do tubo de ensaio no bocal da garrafa.

dobradiças, tipo baú e quatro pernas de madeira de $50 \mathrm{~cm}$ (Figura 1A). Internamente a armadilha foi pintada com tinta esmalte preta (Figura 1C) e externamente com tinta látex branca (Figura 1A). No seu interior havia um fundo falso perfurado, onde foram inseridos os pecíolos de cada folíolo (Figura 1C). A armadilha foi cortada em um dos seus lados, sendo encaixada logo abaixo do fundo falso uma bandeja de ferro $(10 \mathrm{~cm}$ de altura x 39,5cm de largura x 60cm de comprimento), contendo água, onde os pecíolos ficavam imersos (Figura 1B e 1C). Tubos de ensaio, com tampas de rosca perfuradas, foram dispostos externamente à armadilha, totalizando 18 tubos no total. As tampas de rosca foram coladas na madeira, permanecendo fixas. Na parte externa e frontal da armadilha, foram instaladas duas ventoinhas e quatro lâmpadas fluorescentes de $25 \mathrm{~W}$ (uma em cada lado) (Figura 1A) e dois interruptores (um para as lâmpadas e outro para as ventoinhas) na lateral da armadilha (Figuras 1A e 1B).

Foram acondicionados 70 folíolos/ensaio no interior da armadilha. A tampa foi fechada, e os tubos de ensaio foram rosqueados no exterior desta. As lâmpadas foram ligadas à noite, para orientação dos parasitoides que emergissem no período noturno.

B) Armadilha do tipo "garrafa”-Construídas com garrafas tipo "PET” de $2.000 \mathrm{~mL}$, pintadas externamente com tinta látex preta e cortadas transversalmente um pouco acima da sua metade inferior (Figura 2A). Com auxílio de um ferro de solda, foram feitos conjuntos de nove furos com diâmetro aproximado de $2 \mathrm{~mm}$, pouco abaixo da abertura da garrafa, em três posições nos lados desta. Posteriormente, os furos foram recobertos por tecido tipo “voil”, que foram colados externamente à garrafa (Figura 2A), permitindo a aeração do interior da armadilha. Na metade inferior da garrafa, foi colado um anel de $\mathrm{PVC}^{\circledR}$ de $7 \mathrm{~cm}$ de altura, para o encaixe das duas metades da armadilha (Figuras 2A e 2B). As tampas foram perfuradas, sendo encaixados tubos de ensaio e, posteriormente, rosqueadas nos bocais das garrafas. Funis de plástico, com suas extremidades cortadas, foram colados nos bocais das garrafas, para evitar que os parasitoides emergidos pudessem descer pelo tubo de ensaio, retornando ao interior da armadilha (Figuras 2C e 2D). No interior da metade basal da garrafa, foi colado um círculo de acrílico com cinco furos, onde foram inseridos os pecíolos dos folíolos, os quais ficavam imersos em água, para manter a turgidez destes. Foram confeccionadas 12 armadilhas do tipo "garrafa”, cada uma acondicionando quatro folíolos, totalizando 48 folíolos/ensaio. As armadilhas permaneciam sob fonte luminosa no período noturno, para a orientação dos parasitoides. 
As duas armadilhas de emergência propostas demonstraram serem eficientes na obtenção de parasitoides vivos de ovos endofíticos, capturando espécimes de $\boldsymbol{E}$. tingitiphagus. A armadilha do tipo "caixa", por acondicionar uma quantidade maior de folíolos, resultou em um maior número de parasitoides capturados, quando comparada à armadilha do tipo "garrafa".

Como não havia luminosidade no interior das armadilhas, os parasitoides emergidos dirigiam-se à luz, sendo capturados vivos no interior dos tubos de ensaio, nos dois modelos de armadilhas propostas. Os folíolos permaneceram túrgidos e não deteriorados por cerca de 10 dias nos dois tipos de armadilhas, tempo suficiente para que os parasitoides completassem seu ciclo biológico, possibilitando a captura dos adultos emergidos.

Embora o número de parasitoides capturados na armadilha do tipo "caixa” seja maior que na armadilha do tipo "garrafa", seu custo é mais oneroso em relação ao segundo tipo de armadilha. A confecção de armadilhas do tipo "garrafa" é mais simples e rápida, quando comparada ao outro modelo. Contudo, para acondicionar um número semelhante de folíolos que apenas uma armadilha do tipo "caixa" suporta, são necessárias mais de 17 armadilhas do tipo "garrafa". Dessa forma, a utilização de cada um dos modelos propostos dependerá da finalidade da pesquisa a ser realizada, do número de parasitoides vivos necessários e do custo/benefício de cada uma das armadilhas.

\section{CONCLUSÕES}

Os dois modelos de armadilhas foram eficientes na captura de parasitoides vivos. A captura de parasitoides de ovos endofíticos pela armadilha de emergência do tipo "caixa" é superior à da armadilha do tipo "garrafa".

\section{AGRADECIMENTOS}

Aos funcionários da empresa "Plantações E. Michelin Ltda.”, Braz da Silva e Silmar Dias Ferreira, pelas sugestões e pelo auxílio na confecção das armadilhas de emergência.

\section{REFERÊNCIAS}

COSTA, V.A. et al. Observações preliminares sobre o parasitismo de ovos de Leptopharsa heveae (Hemiptera: Tingidae) em Pindorama, SP. Arquivos do Instituto Biológico, v.70, n.2, p.205-206, 2003.

LEWINSOHN, T.M. et al. Inventários bióticos centrados em recursos: Insetos fitófagos e plantas hospedeiras. In: GARAY, I.; DIAS, B. (Orgs.). Conservação da biodiversidade em ecossistemas tropicais. Petrópolis: Vozes, 2001. 430p.

NAKANO, O.; LEITE, C.A. Armadilhas para insetos: pragas agrícolas e domésticas. Piracicaba: FEALQ, 2000. $76 p$.

SCHAUFF, M.E. Collecting and preserving insects and mites. Washington: Museum of Natural History, 1986. 68p. (USDA Miscellaneous Publication, n. 1443). 